\title{
MODELO BIOQUÍMICAMENTE ESTRUCTURADO PARA LA ESTIMACIÓN DE LA EFICIENCIA DE UNA CELDA DE COMBUSTIBLE MICROBIANA
}

\author{
Maxvell Gustavo JIMÉNEZ-ESCAMILLA ${ }^{1 *}$, Claudio GARIBAY-ORIJEL ${ }^{2}$ y \\ Manuel Antonio BORJA-SALIN ${ }^{3}$
}

${ }^{1}$ Unidad Profesional Interdisciplinaria de Biotecnología (UPIBI), Instituto Politécnico Nacional, Av. Acueducto de Guadalupe s.n., barrio La Laguna Ticomán, 07340 Ciudad de México; Universidad Tecnológica de la Mixteca, km. 2.5 carretera a Acatlima, 69000 Huajuapan de León, Oaxaca, México

${ }^{2}$ Labcitec, Camino a Atzacoalco 99, colonia Constitución de la República, 07469 Ciudad de México

${ }^{3}$ Instituto Tecnológico de Toluca, Lázaro Cárdenas s.n., colonia Llano Grande, 52148 Metepec, Estado de México

*Autor para correspondencia; maxvel12001@yahoo.com.mx

(Recibido marzo 2016; aceptado agosto 2017)

Palabras clave: crecimiento microbiano, modelación, bioenergía, energía renovable

\section{RESUMEN}

Se realizó un estudio preliminar de una celda de combustible microbiana a través de los rendimientos microbianos. Se obtuvo un modelo matemático para determinar la cantidad de cargas generadas en el tiempo en la cámara anódica de una celda de combustible microbiana, utilizando Escherichia coli como organismo electrogénico. El modelo se utilizó para estimar la eficiencia eléctrica desde el punto de vista de los rendimientos microbianos como son biomasa, sustrato y producto, y los coeficientes estequiométricos de las especies mencionadas. El modelo matemático se construyó mediante la descripción del crecimiento microbiano a través de un modelo logístico de población, el cual arrojó un coeficiente de determinación entre el modelo y los datos experimentales de $\mathrm{R}^{2}=0.960$ para sustrato $\mathrm{R}^{2}=0.982$ para biomasa. Con este modelo de predicción de cargas eléctricas, en el futuro se procederá primero a medir experimentalmente rendimientos microbianos y coeficientes estequiométricos dado un organismo electrogénico, para estudiar así la factibilidad de implementación de dicha celda.

Key words: microbial growth, modeling, bioenergy, renewable energy

\begin{abstract}
A preliminary study focused on modeling microbial fuel cells through microbial yields was performed. A mathematical model to determine the quantity of charge generated over time in the anodic chamber of a microbial fuel cell, using Escherichia coli as the electrogenic organism, was designed. This model was used in order to estimate the electrical efficiency of microbial yields such as biomass, substrate, and product, and the stoichiometric coefficients of the species aforementioned. The mathematical model constructed described microbial growth using a logistical population model, giving a coefficient of determination of $\mathrm{R}^{2}=0.960$ between the model and the experimental data for the substrate, and $\mathrm{R}^{2}=0.982$ for the biomass. Using this electrical charge
\end{abstract}


prediction model, future studies will focus primarily on measuring the experimental microbial yields and stoichiometric coefficients of electrogenic organisms in order to test the viability of this cell implementation.

\section{INTRODUCCIÓN}

Las celdas de combustible microbiana (CCM) producen energía eléctrica a través de la oxidación de compuestos orgánicos mediante microorganismos. La arquitectura de una celda de combustible en general consta de dos cámaras: la cámara anódica, donde se encuentran los microorganismos, y el medio de cultivo, junto con un electrodo embebido en el medio que funge como aceptor de electrones fijo (ánodo). Los electrones fluyen del ánodo al cátodo a través de un circuito eléctrico externo (Lovley 2006, Ahn y Logan 2012). Una membrana selectiva de protones permite su flujo de la cámara anódica a la cámara catódica. Se coloca una resistencia externa a las cámaras para permitir el flujo de electrones convertidos por los microorganismos del electrodo anódico al catódico, mientras que en la cámara catódica se lleva a cabo la reacción de reducción de oxígeno debida a los protones que fluyeron por la membrana intercambiadora de protones (Fig. 1) (Rabaey et al. 2003, Logan et al. 2005).

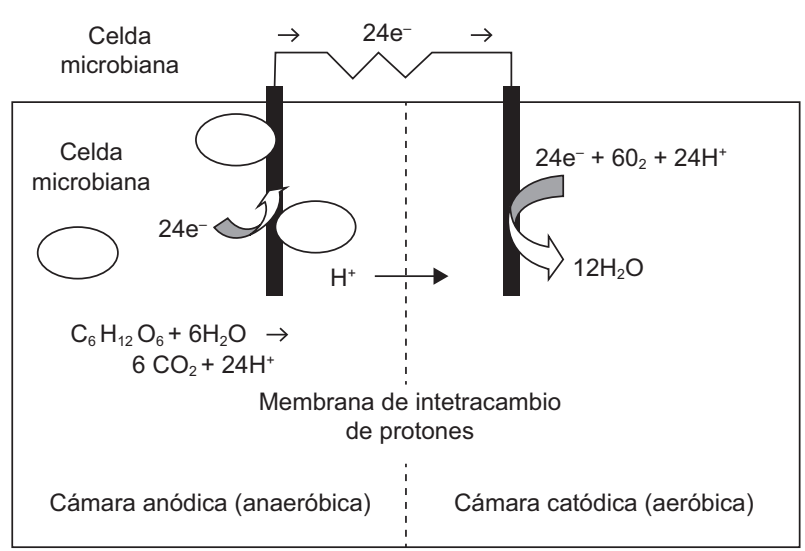

Fig. 1. Esquema del modelo de cámaras separadas para una celda de combustible microbiana (con cátodo y ánodo). Se muestra el balance de glucosa en $\mathrm{CO}_{2}$, iones de hidrógeno y electrones que contribuirán a producir una corriente eléctrica.

Catal et al. (2008) afirman que las investigaciones sobre CCM han empleado gran variedad de fuentes de carbono, como D-glucosa, D-galactosa, fructosa, L-fucosa, 1-ramnosa, d-manosa, d-xilosa, $\mathrm{D}$-arabinosa, d-ribosa, ácido D-galacturónico, ácido D-glucurónico y ácido d-glucónico. Estos mismos autores informan que con el ácido d-glucurónico (480 mg/L) como fuente de carbono se produjeron $1.18 \mathrm{~mA} / \mathrm{m}^{2}$. La sacarosa también se ha utilizado como fuente de carbono para las CCM, y se ha obtenido una densidad de corriente de $1897.3 \mathrm{~mA} / \mathrm{m}^{2}$ (Behera y Ghangrekar 2009). También se ha demostrado que el acetato $(1 \mathrm{~g} / \mathrm{L})$ es una opción como fuente de carbono utilizando CCM con ánodo de fibra de grafito en forma de cepillos, con lo cual se producen $73 \mathrm{~W} / \mathrm{m}^{3}$ (Logan et al. 2007). Al usarse como fuente de carbono, la celulosa $(1 \mathrm{~g} / \mathrm{L})$ presentó una densidad de potencia eléctrica de $188 \mathrm{~mW} / \mathrm{m}^{2}$ (Hassan et al. 2012). Adicionalmente se han realizado notables investigaciones sobre CCM utilizando desechos de plantas de tratamiento de aguas residuales ( $\mathrm{Lu}$ et al. 2009, Nam et al. 2010, Ahn y Logan 2010, Wen et al. 2010, Nimje et al. 2012, Ghadge y Ghangrekar 2015).

Los microorganismos más comúnmente empleados en la CCM han sido Rhodoferax ferrireducens con densidades de carga eléctrica de hasta $158 \mathrm{~mA} / \mathrm{m}^{2}$ (Zhi-Dan et al. 2006); Shewanella oneidensis, que proporcionó una densidad de carga eléctrica de $20 \mathrm{~mA} / \mathrm{m}^{2}$ (Ringeisen et al. 2006); Desulfitobacterium hafniense, que produjo $1.1 \mathrm{~A} / \mathrm{m}^{2}$ (Milliken y May 2007); Geobacter sp., Comamonas sp., Pseudomonas sp., Pelobacter sp., los cuales se emplearon en consorcio en una $\mathrm{CCM}$ con ánodo de grafito granular, obteniéndose una corriente máxima de $21 \mathrm{mAa}$ los 30 días de operación (Freguia et al. 2010), y E. coli K12, que generó $13.4 \mathrm{~A} / \mathrm{m}^{2}$ (Chen et al. 2015). Debido a su versatilidad y robustez en el crecimiento, E. coli se puede presentar como un candidato electrogénico para el estudio de las CCM.

Cuando E. coli crece con glucosa en condiciones anaeróbicas se forman biomasa y compuestos de la fermentación ácida mixta de acuerdo con la ecuación 1 (Rittman y McCarty 2001),

$$
\begin{aligned}
\text { glucosa }= & \text { biomasa }+ \text { productos metabólicos } \\
& +\mathrm{zH}^{+}+\mathrm{ze}^{-}
\end{aligned}
$$

La ecuación (1) sugiere que a partir de la oxidación de la glucosa surgen protones y electrones $(z)$ que pueden utilizarse en una celda de combustible microbiana para generar una diferencia de potencial. 
Sin embargo, la disponibilidad de electrones susceptibles de ser transformados en corriente eléctrica está definida, desde el punto de vista eléctrico, como la cantidad de electrones que aporta cada fuente de carbono por mol. En condiciones anaeróbicas, las reacciones involucradas para convertir la glucosa en algunos de los metabolitos por medio de fermentación, son las siguientes de acuerdo con Rittman y McCarty (2001):

Glucosa en ácido acético:

$\mathrm{C}_{6} \mathrm{H}_{12} \mathrm{O}_{6} \rightarrow 3 \mathrm{C}_{2} \mathrm{H}_{4} \mathrm{O}_{2}$

Glucosa en ácido láctico:

$\mathrm{C}_{6} \mathrm{H}_{12} \mathrm{O}_{6} \rightarrow 2 \mathrm{C}_{3} \mathrm{H}_{6} \mathrm{O}_{3}$

Glucosa en ácido succínico:

$2 \mathrm{C}_{6} \mathrm{H}_{12} \mathrm{O}_{6} \rightarrow 3 \mathrm{C}_{4} \mathrm{H}_{6} \mathrm{O}_{4}+6 \mathrm{e}^{-}+6 \mathrm{H}^{+}$

Glucosa en ácido fórmico:

$\mathrm{C}_{6} \mathrm{H}_{12} \mathrm{O}_{6}+6 \mathrm{H}_{2} \mathrm{O} \rightarrow 6 \mathrm{CH}_{2} \mathrm{O}_{2}+12 \mathrm{e}^{-}+12 \mathrm{H}^{+}$

Glucosa en etanol:

$\mathrm{C}_{6} \mathrm{H}_{12} \mathrm{O}_{6}+12 \mathrm{H}^{+}+12 \mathrm{e}^{-} \rightarrow 3 \mathrm{C}_{2} \mathrm{H}_{6} \mathrm{O}+3 \mathrm{H}_{2} \mathrm{O}$

Si en la oxidación de glucosa mediante $E$. coli en una $\mathrm{CCM}$ sólo se produjeran de manera predominante los compuestos anteriores, habría 6 moles de electrones libres por cada mol de glucosa (ecuación 4) que podrían contribuir a la formación de corriente eléctrica, sin contemplar los 24 electrones que aporta la glucosa por cada mol de la fermentación.

Si se opera por lote una CCM, entonces se cuenta con un límite de electrones que pueden convertirse en electricidad en una CCM en condiciones anaeróbicas, si los productos metabólicos predominantes son los mencionados. El cuadro I muestra los grados de reducción de las variables dinámicas de algunos compuestos tipo para la ecuación 1.

Se han realizado diversos trabajos para mejorar la eficiencia de las celdas de combustible microbianas. Por ejemplo, se han diseñado cepillos de grafito como electrodos, los cuales aumentan el área de contacto en la transferencia de electrones (Ahn et al. 2012). Se han realizado análisis sobre la eficiencia que tendrá una CCM al utilizar resistencias superiores, iguales y mayores a la resistencia intrínseca de la celda (Pinto et al. 2011a), así como estudios acerca de los efectos de utilizar distintas fuentes de carbono en la operación de una CCM (Chae et al. 2009).

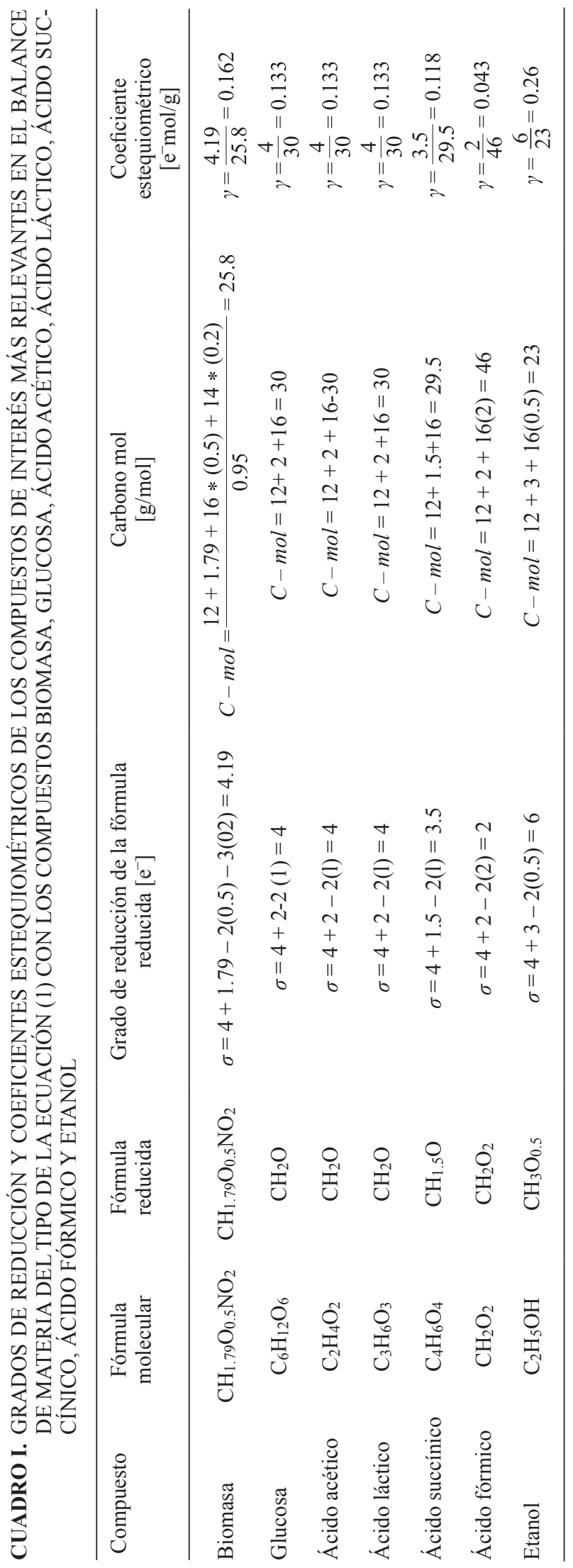


Lo anterior abre un panorama donde una gran variedad de CCM requieren indudablemente ser eficientes para la obtención de electricidad. Por ello, una herramienta poderosa que permite mejorar las celdas de combustible es el modelado matemático, que permite predecir, diseñar, optimizar y controlar el proceso (Oliveira et al. 2013, Ortiz-Martínez et al. 2015).

Se han llevado a cabo estudios para modelar fenómenos que ocurren en las celdas de combustible microbiana, como los procesos de transporte, y reacciones biológicas, químicas y electroquímicas (Ebert et al. 2000, Xavier et al. 2004, Picioreanu et al. 2007, 2010, Pant et al. 2010, Pinto et al. 2010a, b, 2011b, Katuri y Scott 2011). Sin embargo los modelos bioquímicamente estructurados ofrecen la ventaja de determinar las eficiencias de transformación de sustrato a productos metabólicos que son aceptores de electrones (Rittman y McCarty 2001) y, en términos eléctricos, calcular la corriente máxima que podría ofrecer la CCM.

La finalidad del presente trabajo es obtener una expresión alternativa para estimar la eficiencia eléctrica de una CCM desde el punto de vista bioquímico a través de los rendimientos microbianos de consumo de fuente de carbono, productos metabólicos, biomasa y corriente eléctrica medida en una resistencia eléctrica externa, a través de un modelo de crecimiento microbiano.

\section{MATERIALES Y MÉTODOS}

\section{Celda de combustible microbiana}

Se diseñó un sistema de doble cámara (Tao et al. 2015) para la CCM. Se emplearon dos matraces (cámara anódica y cámara catódica) de borosilicato con un volumen de $500 \mathrm{~mL}$, los cuales fueron cortados de forma lateral de tal manera que se empalmaran (Fig. 2). Las cámaras fueron separadas por una membrana de Nafion ${ }^{\circledR} 117$ (Chae et al. 2008, Zhang et al. 2015). Ésta se sumergió en una solución $0.1 \mathrm{M}$ de $\mathrm{H}_{2} \mathrm{SO}_{4}$ por $1 \mathrm{~h} \mathrm{a} 60^{\circ} \mathrm{C}$; enseguida se extrajo de este reservorio y se introdujo en otra solución $0.1 \mathrm{M}$ de $\mathrm{H}_{2} \mathrm{O}_{2}$ por $1 \mathrm{~h}$ a $60{ }^{\circ} \mathrm{C}$. Finalmente se lavó con agua destilada para sumergirla de inmediato en agua destilada por $1 \mathrm{~h}$ a $60{ }^{\circ} \mathrm{C}$ (Oh et al. 2004, Bakhshian et al. 2011), con la finalidad de remover impurezas como iones o compuestos adheridos a los poros. Las cámaras se adhirieron con pegamento de cianocrilato, formándose la unión vidrio-neopreno-electrodo-Nafion ${ }^{\circledR}$ 117-electrodo-neopreno-vidrio (Fig. 2) para minimizar la separación entre los electrodos (Ren et al. 2014, Papaharalabos et al. 2015). Para esterilizar la $\mathrm{CCM}$, ésta se expuso a la luz ultravioleta por $3 \mathrm{~h}$. El modo de operación de la celda fue por lote.

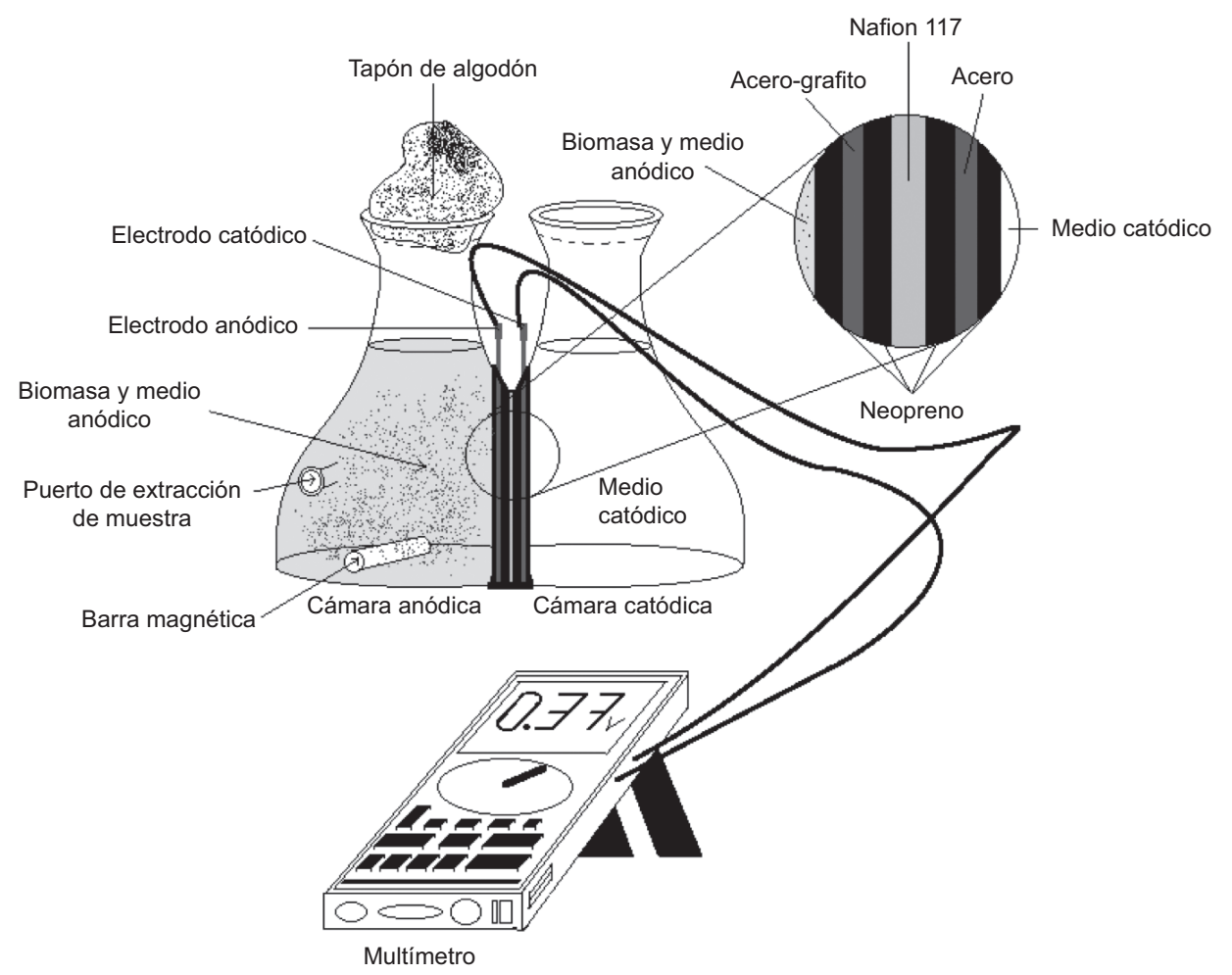

Fig. 2. Representación de la celda de combustible microbiana 


\section{Electrodos}

Los electrodos empleados fueron placas planas de acero inoxidable con orificios de $1 \mathrm{~mm}$ de diámetro (Janicek et al. 2015), área efectiva de $31 \mathrm{~cm}^{2}$ y espesor de $1 \mathrm{~mm}$ (Di Lorenzo et al. 2010). El ánodo se forró con tela de grafito (Rabaey et al. 2003, Logan et al. 2007, Dumas et al. 2008). Ésta se sometió a un tratamiento de limpieza sumergiéndola en la celda con $1 \mathrm{M}$ de $\mathrm{NaOH}$ por 30 min; enseguida se introdujo en una solución de $\mathrm{HCl}$ a $1 \mathrm{M}$ por 30 min y finalmente remojó por $1 \mathrm{~h}$ en agua destilada para remover sales e iones remanentes. Lo anterior se llevó a cabo de acuerdo con los informado por Chaudhuri y Lovley (2003). El cátodo fue una placa de acero inoxidable de la misma dimensión que el ánodo.

\section{Electrolito en la cámara catódica}

El electrolito en la cámara catódica, conocido como medio catódico (MC), estuvo compuesto (en g/L) por: $\mathrm{K}_{2} \mathrm{HPO}_{4}$ (8.7), $\mathrm{KH}_{2} \mathrm{PO}_{4}$ (6.8), $\mathrm{NaCl}$ (2.92) y ferrocianuro de potasio (3.3) (Oh et al. 2004, Mohan et al. 2008, Liu et al. 2015). Los compuestos anteriores se emplearon para ayudar a los iones de hidrógeno a reducirse con el oxígeno (Park y Zeikus 2000, Daniel et al. 2009, Rodrigo et al. 2010, Freguia et al. 2010).

\section{Medio de cultivo en la cámara anódica}

El medio de cultivo de la cámara anódica, conocido como medio anódico (MA), consistió en $\mathrm{NaCl}$ $(0.5 \mathrm{~g} / \mathrm{L}),\left(\mathrm{NH}_{4}\right)_{2} \mathrm{SO}_{4}(1 \mathrm{~g} / \mathrm{L})$, extracto de levadura $(1 \mathrm{~g} / \mathrm{L}), \mathrm{K}_{2} \mathrm{HPO}_{4}(17.4 \mathrm{~g} / \mathrm{L}), \mathrm{KH}_{2} \mathrm{PO}_{4}(13.6 \mathrm{~g} / \mathrm{L})$ y glucosa $(10 \mathrm{~g} / \mathrm{L})$. También se agregó fumarato ferroso en una concentración de $0.1 \mathrm{~g} / \mathrm{L}$, logrando su disolución. El compuesto anterior actúa como mediador de los electrones producidos por el metabolismo del microorganismo electrogénico, hacia el electrodo anódico (Park y Zeikus 2002, Esteve-Núñez et al. 2005, Abrevaya et al. 2011, Zhao et al. 2012).

\section{Inóculo y microorganismo de CCM}

Se empleó Escherichia coli K12 por su versatilidad de crecimiento y debido a que se ha utilizado como organismo electrogénico en investigaciones previas (Park et al. 2000, Kim et al. 2002, Ieropoulos et al. 2005, Zhao et al. 2006, Zhao et al. 2012, Reiche et al. 2012, Chen et al. 2015). La cepa se mantuvo en medio agar Luria Bertani (LB) a $4^{\circ} \mathrm{C}$. Con un asa microbiológica se tomó una muestra de $E$. coli en medio agar LB para inocular un matraz Erlenmeyer de $250 \mathrm{~mL}$ con $50 \mathrm{~mL}$ de MA. El matraz se incubó por $24 \mathrm{~h}$ a $37^{\circ} \mathrm{C}$ y a $200 \mathrm{rpm}$. Del cultivo anterior se tomó una alícuota de $9 \mathrm{~mL}$ para inocular la cámara anódica con MA. La concentración inicial de biomasa en la cámara anódica fue de $0.08 \mathrm{~g} / \mathrm{L}$, con lo que se obtuvo un volumen total de $450 \mathrm{~mL}$. La cámara anódica fue burbujeada con nitrógeno para preservar condiciones anaeróbicas. La cámara catódica contenía $450 \mathrm{~mL}$ de $\mathrm{MC}$ y se mantuvo sin agitación, abierta a la atmósfera (Feng et al. 2008, Wen et al. 2011, Quan et al. 2012) y sin inocular (Fig. 2). La CCM se introdujo en una incubadora a $37 \pm 1{ }^{\circ} \mathrm{C}$ (Kim et al. 2002) y en agitación para evitar la formación de biopelículas y mantener un voltaje alto a esta temperatura (Liu et al. 2012). Todos los experimentos se realizaron por triplicado.

\section{Análisis de biomasa}

Se tomó una muestra de la cámara anódica $(1 \mathrm{~mL})$ para cuantificar el crecimiento microbiano por absorbancia a $600 \mathrm{~nm}$, con un espectrofotómetro Jenway 7310 (Jenway, EUA). La medición de absorbancia se transformó en sólidos suspendidos totales (SST) mediante la obtención de una curva de calibración (APHA 1998), como se muestra en la siguiente ecuación:

$B\left[\frac{g}{L}\right]=\left(973.3\left[\frac{g}{L}\right]\right) * A+37.7\left[\frac{g}{L}\right]$

La ecuación (7) se obtuvo al graficar datos experimentales de biomasa $(\mathrm{g} / \mathrm{L})$ contra absorbancia para un mismo tiempo y ajustar a una recta. En esta forma la cantidad $B[\mathrm{~g} / \mathrm{L}]$ proporciona la correspondiente biomasa cuando se mide la absorbancia $A$ (la absorbancia no tiene unidades), que se encuentra en una toma de muestra. Se observa que la ecuación es una recta, la cual indica que la relación de absorbancia y biomasa es lineal; sin embargo, como se obtuvo experimentalmente tiene el término de la ordenada al origen distinto de cero $(37.7[\mathrm{~g} / \mathrm{L}])$, pero en magnitud menor a la pendiente $(973.7[\mathrm{~g} / \mathrm{L}])$, por lo que su contribución no es fuerte en la estimación de la biomasa.

Con esta ecuación sólo se mide la absorbancia en una muestra de $1 \mathrm{~mL}$ y se calcula la biomasa presente en la cámara anódica de la CCM.

\section{Análisis de sustrato}

La concentración de glucosa y productos metabólicos se analizó mediante la técnica de cromatografía líquida de alta eficacia (HPLC, por sus siglas en inglés) con un cromatógrafo marca Varian Prostar (Varian, EUA), realizando las diluciones pertinentes y ubicando las muestras en el intervalo de linealidad. Se empleó una columna Aminex HPX-87H de exclusión de iones de $300 \times 7.8 \mathrm{~mm}$ con detector de índice de refracción. La fase móvil utilizada fue $\mathrm{H}_{2} \mathrm{SO}_{4}$ al $5 \times$ $10^{-3} \mathrm{~N}$ a un flujo de $0.6 \mathrm{~mL} / \mathrm{min}$. 


\section{Medición de voltaje directo}

Las mediciones de voltaje se realizaron a circuito abierto con un multímetro digital UNI-T ${ }^{\circledR}$ modelo UT71E, el cual fue conectado a las terminales de los electrodos anódico y catódico.

\section{Formulación del modelo}

El modelo propuesto para la descripción poblacional se estableció a través de la siguiente ecuación diferencial lineal en el tiempo:

$\frac{d x}{d t}=\mu x$

La propuesta de la velocidad de crecimiento se estableció mediante el modelo logístico de población (Zwietering et al. 1990, Skinner et al. 1994, López et al. 2004), el cual se empleó para describir el crecimiento microbiano debido a su versatilidad, ya que no incorpora cantidades como parámetros que involucren el metabolismo interno de la célula ni concentraciones de afinidad o factores limitantes. En este modelo sólo se requieren las concentraciones iniciales y finales, así como el cálculo de la velocidad máxima de crecimiento en la fase exponencial.

$\mu=\mu_{\max }\left(1-\frac{x}{x_{\max }}\right)$

Los productos metabólicos y el sustrato se comportan de acuerdo con las ecuaciones diferenciales siguientes (Rittman y McCarty 2001) a través de los respectivos rendimientos $Y_{x / S}, Y_{P / x}$ :

$\frac{d S}{d t}=-\frac{1}{Y_{x / S}} \frac{d x}{d t}$,

$\frac{d P}{d t}=Y_{P / x} \frac{d x}{d t}$.

Al sustituir la velocidad de crecimiento descrita por la ecuación (9), en la ecuación (8), se resolvió la ecuación diferencial para la concentración de biomasa ecuación (8). Una vez obtenida la expresión para la concentración de biomasa $(x)$, ésta se sustituyó en las ecuaciones (10) y (11) para encontrar las funciones que describen la concentración de sustrato $(S)$ y producto $(P)$. Para estimar el desempeño del modelo se valoraron las soluciones analíticas de las ecuaciones diferenciales con los datos experimentales mediante el coeficiente de determinación $\mathrm{R}^{2}$, el cual se calculó a través del valor cuadrático medio (RMS, por sus siglas en inglés), que de acuerdo con López et al. (2004) indica una medida de la dispersión de los valores medidos o experimentales de una variable $y$ respecto de los valores teóricos de dicha variable. El coeficiente de determinación se calcula de la siguiente forma:

$R^{2}=\left(1-\frac{R M S}{S_{y}^{2}}\right) \times 100 \%$,

$R M S=\sum_{i=1}^{n} \frac{\left(y_{i}^{\exp }-y_{i}^{s i m}\right)^{2}}{n-1}$,

$S_{y}^{2}=\sum_{i=1}^{n} \frac{\left(y_{i}^{e x p}-\bar{y}\right)^{2}}{n}$.

donde $y_{i}^{\text {exp }}$ es el valor experimental de la variable de interés $y ; y_{i}^{\text {sim }}$ el valor simulado u obtenido teóricamente por el modelo matemático; $\bar{y}$ el promedio de los valores medidos o experimentales de $y ; S_{y}^{2}$ la varianza total, que es una medida cuadrática de la dispersión de los valores medidos o experimentales respecto del valor medio, y, finalmente, $n$ es el número de datos medidos.

\section{Balance de cargas eléctricas}

Si bien la cantidad de electrones susceptibles de transformarse en energía es importante, más aún es la rapidez a la que se transportan dichos electrones del ánodo al cátodo. Esta cantidad es la corriente eléctrica, que se expresa como:

$i=\frac{d q}{d t}$

Por tal razón, hay una tasa de transformación de electrones de todas las cantidades presentes en la cámara anódica. Dichas razones se calculan al diferenciar en el tiempo la ecuación (1) y despejar la cantidad de cargas adheridas por unidad de tiempo en el ánodo, de acuerdo con:

$2 \frac{d e^{-}}{d t}=\gamma_{S} \frac{d S}{d t}-\sum_{j=1}^{m} \gamma_{j} \frac{d F_{j}}{d t}$

donde el factor 2 del lado izquierdo se debe al factor doble $z$ de la ecuación (1). El coeficiente $\gamma_{s}$ estequiométrico indica la cantidad de carga eléctrica-mol por cada gramo por litro de fuente de carbono, mientras que $\gamma_{j}$ indica la cantidad de carga eléctrica-mol por cada gramo por litro de compuesto químico (Cuadro I). El número total de compuestos químicos se denota por $m$. La ecuación (16) expresa la forma en que se transforman las cargas residuales susceptibles de ser utilizadas como corriente eléctrica debido al consumo de glucosa y a que algunos de los electrones forman parte de la biomasa y productos metabólicos.

Se recuerda que $\frac{d P}{d t}=Y_{P, x} \frac{d x}{d t}, \frac{d x}{d t}=-Y_{x s} \frac{d S}{d t}$, de tal forma que estas expresiones se sustituyeron en la ecuación (16) para obtener: 
$2 \frac{d e^{-}}{d t}=-\gamma_{S} \frac{d S}{d t}+\gamma_{x} Y_{x / S} \frac{d S}{d t}+\sum_{j=1}^{m} \gamma_{j} Y_{P / x} Y_{x / S} \frac{d S}{d t}$

Se simplificó la ecuación anterior al definir

$i=\frac{d e^{-}}{d t}, i=\frac{1}{2}\left(-\gamma_{S}+\gamma_{x} Y_{x / S}+\sum_{j=\mathrm{i}}^{m} \gamma_{j} Y_{P / S}\right) \frac{d S}{d t}$

La ecuación (18) permite calcular la variación temporal de cargas en el ánodo una vez que: 1) sean obtenidos los rendimientos microbianos en la cinética de crecimiento de E. coli en la celda de combustible microbiana, 2) se sustituyan los coeficientes estequiométricos del cuadro I y 3 ) se resuelva analíticamente la ecuación (8) para obtener la expresión matemática de $\mathrm{dS} / \mathrm{dt}$.

\section{RESULTADOS Y DISCUSIÓN}

La CCM operó durante $30 \mathrm{~h}$ continuas dentro de una incubadora a $37 \pm 1^{\circ} \mathrm{C}$. La cámara anódica se mantuvo con agitación magnética a $155 \mathrm{rpm}$. Se agregó una concentración inicial de inóculo de $0.08 \mathrm{~g} / \mathrm{L}$, que previamente contenía material del MA. El volumen total de la cámara anódica se llevó a 450 $\mathrm{mL}$. La cámara catódica contenía $450 \mathrm{~mL}$ del MC. Al cabo de 15 h de operación la concentración de glucosa fue consumida en su totalidad. A las 10 $\mathrm{h}$ de operación el microorganismo entró en fase estacionaria.

En la figura 3 se observa el crecimiento debido al consumo de glucosa por $E$. coli y la formación de productos metabólicos, principalmente ácidos acético, láctico, succínico y fórmico, así como etanol, ya que los otros productos aparecen a nivel de trazas.

El voltaje a circuito abierto se midió en los bornes de la cámara anódica y catódica, mostrando estabili-

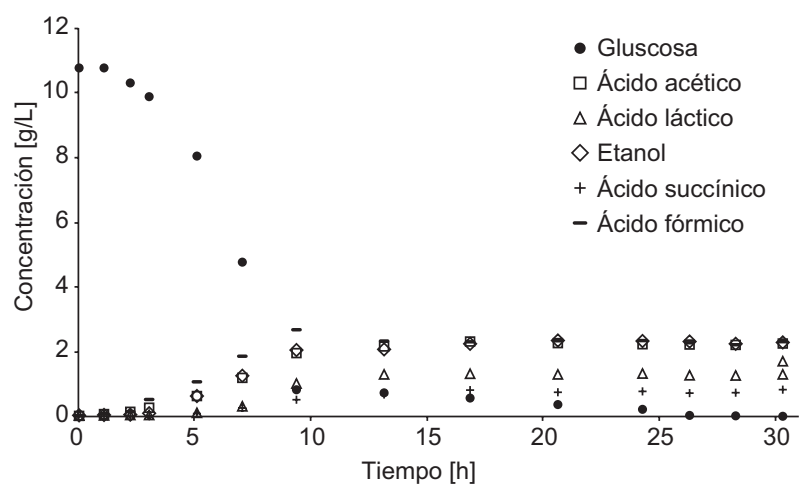

Fig. 3. Consumo temporal de glucosa y generación de productos en la celda de combustible microbiana dad después de $14 \mathrm{~h}$. En la figura 4 se muestran los valores de voltaje en el tiempo.

Debido a la forma geométrica del diseño de la celda, ésta se comporta como celda capacitiva (Uría et al. 2011, Malvankar et al. 2012, Bonanni et al. 2012, Deeke et al. 2012, Choi 2015); esto favoreció la formación de cargas en paralelo de los electrodos, lo cual se manifiesta en un voltaje a circuito abierto. Cabe mencionar que el voltaje obtenido (en las condiciones de operación de la presente (CM), es del mismo orden de magnitud que en las CCM descritas por Kim et al. (2002) (0.52 V), Zhao et al. (2006) $(0.697 \mathrm{~V})$ e Ieropolus et al. (2005) (0.8 V). Una vez almacenada la carga máxima, se llevó a cabo la medición de corriente eléctrica para obtener la densidad de corriente, siendo ésta (la corriente por unidad de área) la que se calcula como corriente medida dividida entre el área del ánodo $\left(31 \mathrm{~cm}^{2}\right)$.

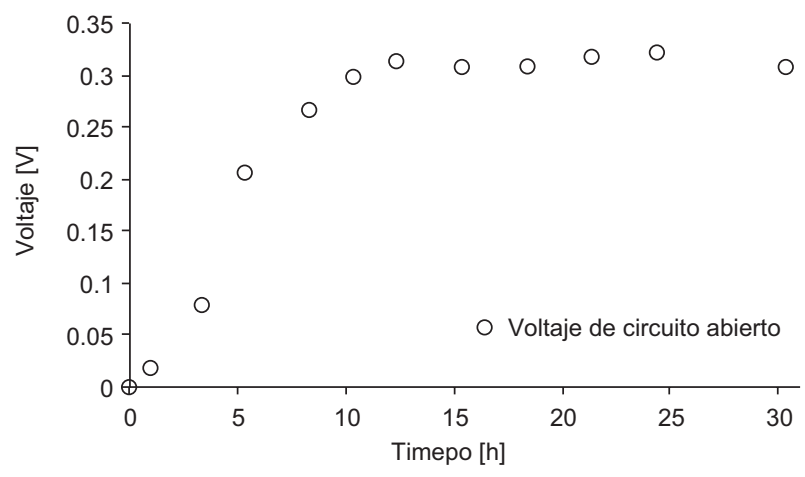

Fig. 4. Voltaje a circuito abierto medido en los bornes de la celda de combustible microbiana

Se calculó la potencia por unidad de volumen $(P=(V \times i) / v))$. La figura 5 muestra, en el sentido de las manecillas del reloj, los puntos de voltaje y densidad de potencia para las resistencias respectivas como $0,14120,1690,560$ y $57 \Omega$. Después se observó que la corriente que entrega la máxima potencia de la CCM correspondió a una resistencia de $1690 \Omega$. Debido a que el propósito de un sistema energético es que proporcione la máxima potencia posible, se llevó a cabo la medición de corriente para una carga externa de $1690 \Omega$. Se midió la corriente eléctrica inmediatamente después de alcanzar el máximo voltaje a las $14 \mathrm{~h}$ de operación, obteniéndose un valor de $0.057 \mathrm{~mA}$, en tanto que la densidad de corriente para esta resistencia fue de $0.02 \mathrm{~mA} / \mathrm{m}^{2}$. La densidad de corriente es muy baja al compararse con otras CCM (0.058 A $/ \mathrm{m}^{2}$ [Reiche y Kirkwood 2012], $0.073 \mathrm{~A} / \mathrm{m}^{2}$ en [Rodrigo et al. 2009] y hasta $8.2 \mathrm{~A} / \mathrm{m}^{2}$ 
[Logan et al. 2007]). La diferencia fundamental radica en que en dichas CCM los organismos eran puramente electrogénicos, por lo que el aceptor de electrones era un metal, mientras que en el caso de E. coli se trata de ácidos orgánicos. Es importante mencionar que Reiche y Kirkwood (2012) utilizaron una alta concentración de fuente de carbono $(19 \mathrm{~g} / \mathrm{L}$ glicerol) distinta a la empleada en el presente trabajo.

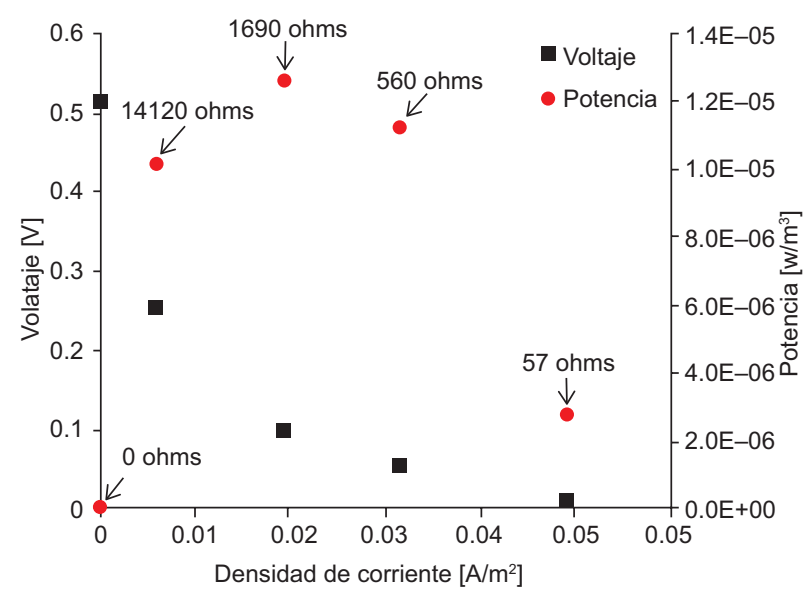

Fig. 5. Cálculo de potencia y densidad de corriente en las resistencias ilustradas de $0,14120,1690,560$ y $57 \Omega$

Se calculó la velocidad de crecimiento máxima en la fase exponencial para la parte lineal de los datos experimentales de biomasa $\left(\mu_{\max }=0.49\left[\mathrm{~h}^{-1}\right]\right)$. Al resolver analíticamente la ecuación (8) mediante la sustitución de la ecuación (9), utilizando la información de las concentraciones final $\left(\mathrm{x}_{\max }=1.083[\mathrm{~g} / L]\right)$ e inicial $\left(\mathrm{x}_{\max }=0.08[\mathrm{~g} / L]\right)$, así como la velocidad de crecimiento máxima, se obtuvo la solución para la concentración de biomasa como función del tiempo:

$x(t)=\frac{1.083[g / L]}{1+12.537 \mathrm{e}^{-0.49\left[\mathrm{~h}^{-1}\right] \mathrm{t}}}$

El cociente $\left(x_{\max }-x_{0}\right) / x_{0}$ de la solución analítica corresponde al factor 12.537 de la ecuación (19). Los puntos experimentales de biomasa y la solución analítica se grafican en la figura 6.

Con los datos experimentales de concentración de glucosa (sustrato) recabados se obtuvo el rendimiento microbiano (g-biomasa/g-sustrato), el cual arrojó un valor de $Y_{X / S}=0.092$. Una vez obtenida, la solución en el tiempo para la concentración de biomasa (ecuación 19) se sustituyó en la ecuación (10) y se integró en dicha expresión para obtener la solución analítica al modelo de la concentración de glucosa.

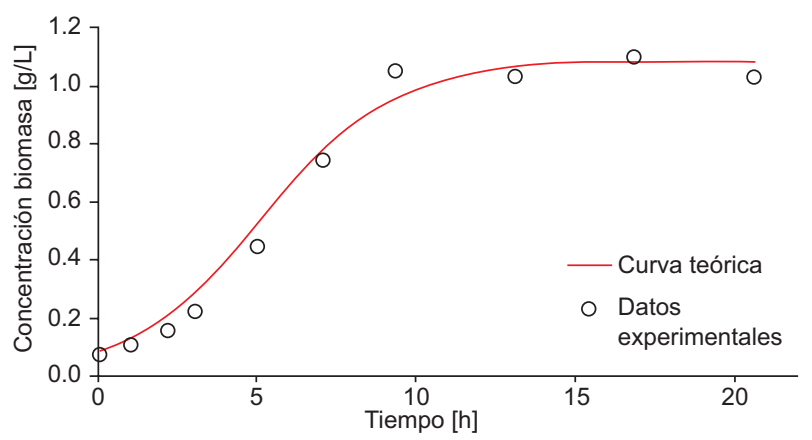

Fig. 6. Concentración experimental de biomasa (o) y solución analítica de la ecuación diferencial logística para la biomasa (línea continua) como función del tiempo, en la cámara anódica de la celda de combustible microbiana

$$
\mathrm{S}(\mathrm{t})=11.561[\mathrm{~g} / L]-\frac{11.657[\mathrm{~g} / L]}{1+12.537 \mathrm{e}^{-0.49\left[\mathrm{~h}^{-1}\right] \mathrm{t}}}
$$

Los datos experimentales de concentración de glucosa y la gráfica de la ecuación (14) se muestran en la figura 7.

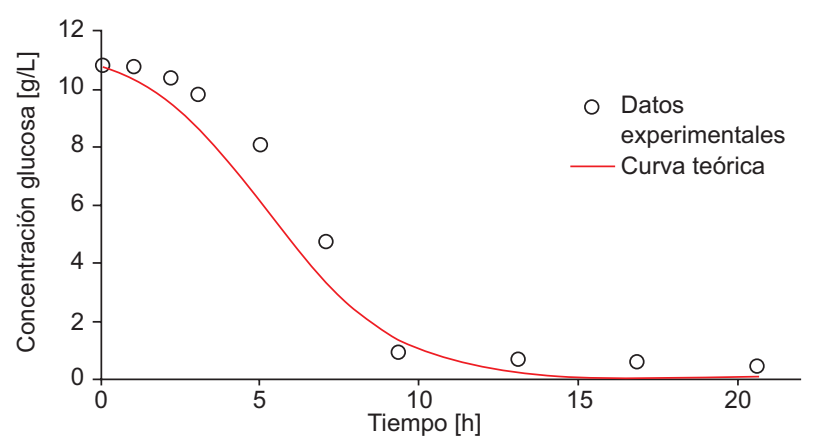

Fig. 7. Concentración experimental de glucosa (o) y la solución analítica de la ecuación diferencial (5) para la glucosa (línea continua) como función del tiempo, dentro de la cámara anódica de la celda de combustible microbiana

La ecuación (19) permitió resolver de manera conjunta la ecuación diferencial (11) para los productos, proporcionando la descripción del comportamiento de los productos como función del tiempo. Los datos experimentales de la concentración de los productos ácido acético, láctico, succínico y fórmico, así como etanol, permitieron calcular los rendimientos por producto. A continuación se muestran las soluciones analíticas para los comportamientos temporales de los ácidos acético $(\mathrm{A}[\mathrm{t}])$, láctico $(\mathrm{L}[\mathrm{t}])$, succínico $(\mathrm{Sc}[\mathrm{t}])$ $y$ fórmico $(\mathrm{F}[\mathrm{t}])$, y del etanol $(\mathrm{E}[\mathrm{t}])$, así como sus respectivas gráficas (Figs. 8, 9, 10, 11 y 12).

$\mathrm{A}(\mathrm{t})=\frac{2.308[\mathrm{~g} / L]\left(1-\mathrm{e}^{-0.49\left[\mathrm{~h}^{-1}\right] \mathrm{t}}\right)}{1+12.537 \mathrm{e}^{-0.49\left[\mathrm{~h}^{-1}\right] \mathrm{t}}}$, 
$\mathrm{L}(\mathrm{t})=\frac{1.329[g / L]\left(1-\mathrm{e}^{-0.49\left[\mathrm{~h}^{-1}\right] \mathrm{t}}\right)}{1+12.537 \mathrm{e}^{-0.49\left[\mathrm{~h}^{-1}\right] \mathrm{t}}}$,

$\mathrm{Sc}(\mathrm{t})=\frac{0.816[g / L]\left(1-\mathrm{e}^{-0.49\left[\mathrm{~h}^{-1}\right] \mathrm{t}}\right)}{1+12.537 \mathrm{e}^{-0.49\left[\mathrm{~h}^{-1}\right] \mathrm{t}}}$,

$\mathrm{F}(\mathrm{t})=\frac{2.308[\mathrm{~g} / L]\left(1-\mathrm{e}^{-0.49\left[\mathrm{~h}^{-1}\right] \mathrm{t}}\right)}{1+12.537 \mathrm{e}^{-0.49\left[\mathrm{~h}^{-1}\right] \mathrm{t}}}$,

$\mathrm{E}(\mathrm{t})=\frac{2.363[\mathrm{~g} / L]\left(1-\mathrm{e}^{-0.49\left[\mathrm{~h}^{-1}\right] \mathrm{t}}\right)}{1+12.537 \mathrm{e}^{-0.49\left[\mathrm{~h}^{-1}\right] \mathrm{t}}}$

Con los datos experimentales de las curvas anteriores se calcularon los rendimientos de los productos metabólicos (cuadro II), así como los valores de los coeficientes de determinación de las soluciones analíticas con los puntos experimentales. Como se muestra en el cuadro II, los coeficientes de determinación son cercanos a 1 , por lo que la ecuación

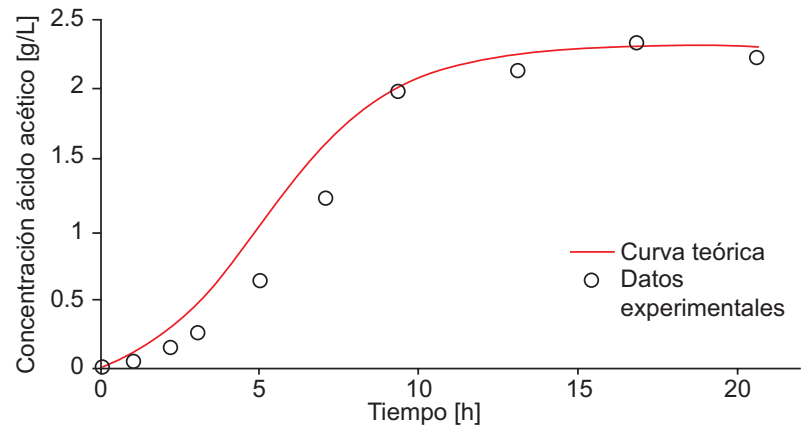

Fig. 8. Concentración experimental de ácido acético (o) y la solución analítica de la ecuación diferencial (6) para el ácido acético (línea continua) como función del tiempo, dentro de la cámara anódica de la celda de combustible microbiana

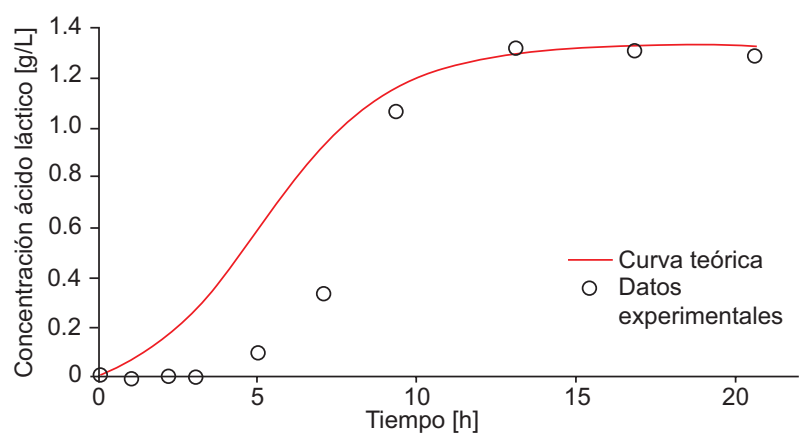

Fig. 9. Concentración experimental de ácido láctico (o) y la solución analítica de la ecuación diferencial (6) para ácido láctico (línea continua) como función del tiempo, dentro de la cámara anódica de la celda de combustible microbiana

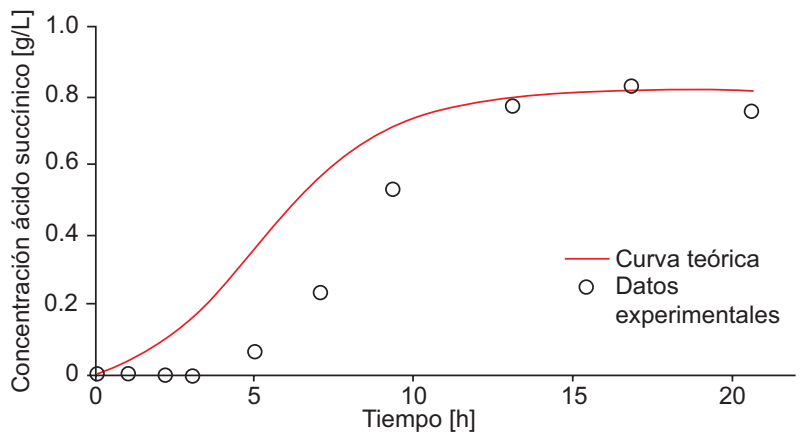

Fig. 10. Concentración experimental de ácido succínico (o) y la solución analítica de la ecuación diferencial (6) para ácido succínico (línea continua) como función del tiempo, dentro de la cámara anódica de la celda de combustible microbiana

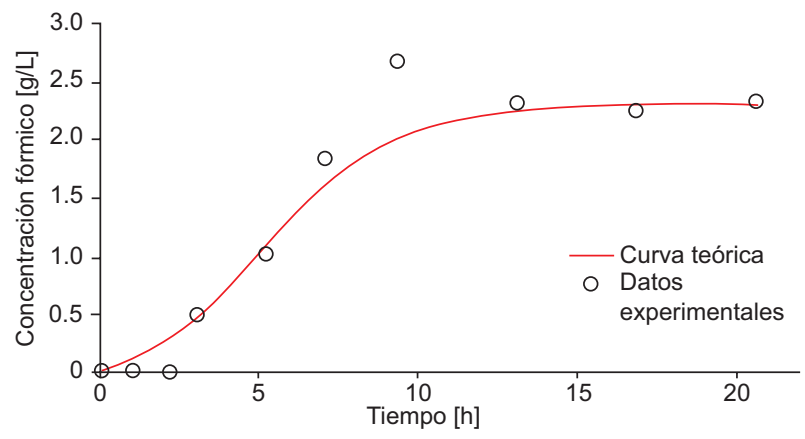

Fig. 11. Concentración experimental de ácido fórmico (o) y la solución analítica de la ecuación diferencial (6) para ácido fórmico (línea continua) como función del tiempo, dentro de la cámara anódica de la celda de combustible microbiana

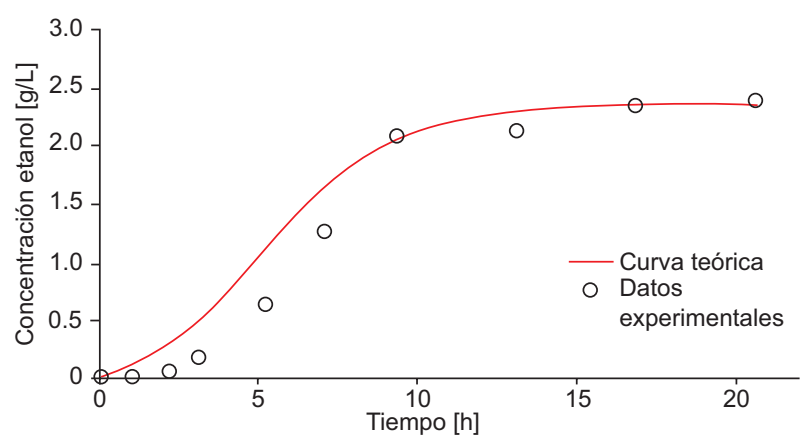

Fig. 12. Concentración experimental de etanol (o) y la solución analítica de la ecuación diferencial (6) para etanol (línea continua) como función del tiempo, dentro de la cámara anódica de la celda de combustible microbiana

logística modela el comportamiento microbiano del sistema. Sin embargo, el modelo diverge ligeramente en las primeras horas para los productos como ácido láctico y succínico, ya que el modelo arroja un 
CUADRO II. RENDIMIENTOS DE PRODUCTOS POR BIOMASA Y POR SUSTRATO, COEFICIENTE ESTEQUIOMÉTRICO Y VALOR DEL COEFICIENTE DE DETERMINACIÓN DEL MODELO LOGÍSTICO PARA CADA COMPUESTO

\begin{tabular}{lcccc}
\hline $\begin{array}{l}\text { Productos } \\
\text { metabólicos }\end{array}$ & $\begin{array}{c}\text { Rendimiento } Y_{P / X} \\
\text { g-producto/g-biomasa }\end{array}$ & $\begin{array}{c}\text { Rendimiento } Y_{P / S} \\
\text { g-producto/g-sustrato] }\end{array}$ & $\begin{array}{c}\text { Coeficiente } \\
\text { estequiométrico } \\
{\left[\frac{e^{-} \text {mol }}{g / l}\right]}\end{array}$ & $\begin{array}{c}\text { Coeficiente de } \\
\text { determinación R }\end{array}$ \\
\hline Biomasa & 1 & 0.092 & 0.162 & 0.982 \\
Glucosa & 10.757 & 1 & 0.133 & 0.960 \\
Ácido acético & 2.218 & 0.206 & 0.133 & 0.963 \\
Ácido láctico & 1.266 & 0.117 & 0.133 & 0.841 \\
Ácido succínico & 0.732 & 0.068 & 0.118 & 0.820 \\
Ácido fórmico & 2.283 & 0.226 & 0.043 & 0.960 \\
Etanol & 2.283 & 0.212 & 0.260 & 0.957 \\
\hline
\end{tabular}

\section{NOMENCLATURA}

\begin{tabular}{|c|c|c|}
\hline Variable & Símbolo & Unidades \\
\hline Absorbancia & $A$ & Adimensional \\
\hline Carga eléctrica & $q$ & {$[\mathrm{C}]$} \\
\hline $\begin{array}{l}\text { Coeficiente estequiométrico de } \\
\text { carga eléctrica de producto }\end{array}$ & $\gamma_{P}$ & {$[\mathrm{e}-\mathrm{mol} / \mathrm{g} / \mathrm{L}]$} \\
\hline $\begin{array}{l}\text { Coeficiente estequiométrico de } \\
\text { carga eléctrica del sustrato }\end{array}$ & $\gamma_{S}$ & [e-mol/g/L] \\
\hline Concentración de biomasa & $x$ & {$[\mathrm{~g} / \mathrm{L}]$} \\
\hline Concentración de producto & $P$ & {$[\mathrm{~g} / \mathrm{L}]$} \\
\hline Concentración de sustrato & $S$ & {$[\mathrm{~g} / \mathrm{L}]$} \\
\hline Corriente eléctrica & $i$ & {$[\mathrm{~A}]$} \\
\hline Eficiencia & $\eta$ & Adimensional \\
\hline Especie química iésima & $F_{j}$ & {$[\mathrm{~g} / \mathrm{L}]$} \\
\hline Coeficiente de determinación & $R^{2}$ & Adimensional \\
\hline Número de datos & $n$ & Adimensional \\
\hline Peso seco & $B$ & {$[\mathrm{~g} / \mathrm{L}]$} \\
\hline Potencia eléctrica & $P$ & {$[\mathrm{w}]$} \\
\hline $\begin{array}{l}\text { Rendimiento de biomasa por } \\
\text { sustrato }\end{array}$ & $Y_{x / S}$ & Adimensional \\
\hline $\begin{array}{l}\text { Rendimiento de producto por } \\
\text { biomasa }\end{array}$ & $Y_{P / x}$ & Adimensional \\
\hline Residuo cuadrático medio & $R M S$ & {$\left[\mathrm{~g}^{2} / \mathrm{L}^{2}\right]$} \\
\hline Tiempo & $t$ & {$[\mathrm{~s}]$} \\
\hline $\begin{array}{l}\text { Valor iésimo numérico } \\
\text { experimental }\end{array}$ & $y_{i}^{\exp }$ & {$[\mathrm{g} / \mathrm{L}]$} \\
\hline $\begin{array}{l}\text { Valor iésimo numérico } \\
\text { simulado }\end{array}$ & $y_{i}^{\text {sim }}$ & {$[\mathrm{g} / \mathrm{L}]$} \\
\hline Valor promedio & $\bar{y}$ & {$[\mathrm{~g} / \mathrm{L}]$} \\
\hline Varianza total & $S_{y}^{2}$ & {$\left[\mathrm{~g}^{2} / \mathrm{L}^{2}\right]$} \\
\hline $\begin{array}{l}\text { Velocidad máxima de } \\
\text { crecimiento }\end{array}$ & $\mu_{\max }$ & {$\left[\mathrm{h}^{-1}\right]$} \\
\hline Voltaje & $V$ & [volts] \\
\hline Volumen & $v$ & {$\left[\mathrm{~m}^{3}\right]$} \\
\hline
\end{tabular}

aumento instantáneo en los productos como resultado del consumo de glucosa, pero en la realidad los productos anteriores se forman en etapas posteriores a la conversión de glucosa en ácido láctico y succínico.
El modelo logístico no contempla que ocurran estos fenómenos. En el cuadro II se agrega la información expuesta también en el cuadro I, para sustituir los coeficientes estequiométricos en la ecuación (18).

Al sustituir los valores de los rendimientos del cuadro II en la ecuación (18) se obtuvo la siguiente expresión:

$$
i=-8.57 \times 10^{-4}\left[\frac{\mathrm{e}^{-} \mathrm{mol}}{\mathrm{g} / \mathrm{L}}\right] \frac{d S}{d t}
$$

Sustituyendo $1 \mathrm{~mol}=6.023 \times 10^{23}$ unidades,

$$
\begin{aligned}
& i=-\left(8.57 \times 10^{-4} \times 6.023 \times 10^{23}\left[\frac{\mathrm{e}^{-}}{\mathrm{g} / \mathrm{L}}\right] \frac{d S}{d t},\right. \\
& i=-\left(5.161 \times 10^{20}\left[\frac{\mathrm{e}^{-}}{\mathrm{g} / \mathrm{L}}\right] \frac{d S}{d t}\right.
\end{aligned}
$$

la conversión coulómbica de un electrón es: $1 \mathrm{e}^{-}=$ $1.6 \times 10^{-19} \mathrm{C}$

$i=-82.57\left\lceil\frac{\mathrm{c}}{\mathrm{g} / \mathrm{L}}\right\rceil \frac{d S}{d t}$

Para la ecuación anterior se calculó el término $d S / d t$ de la ecuación (20), con el fin de obtener la corriente eléctrica teórica máxima generada por la actividad microbiana sin transitar por una resistencia externa, como función del tiempo. Al ser sustituida la derivada temporal de $S(t)$, se obtuvo la siguiente expresión para la corriente:

$i(t)=\frac{1.64[\mathrm{~A}] \mathrm{e}^{-0.49\left[\mathrm{~h}^{-1}\right] \mathrm{t}}}{\left(1+12.537 \mathrm{e}^{-0.49\left[\mathrm{~h}^{-1}\right] \mathrm{t}}\right)^{2}}$.

En la figura 13 se muestra la intensidad de corriente eléctrica teórica generada por la actividad microbiana susceptible de convertirse en corriente 
medible en una resistencia externa. Se observa y calcula que el valor máximo que ofrecería el sistema es de $31 \mathrm{~mA}$. Si la CCM operara en modo continuo, se produciría como cota superior $i_{x}=31 \mathrm{~mA}$.

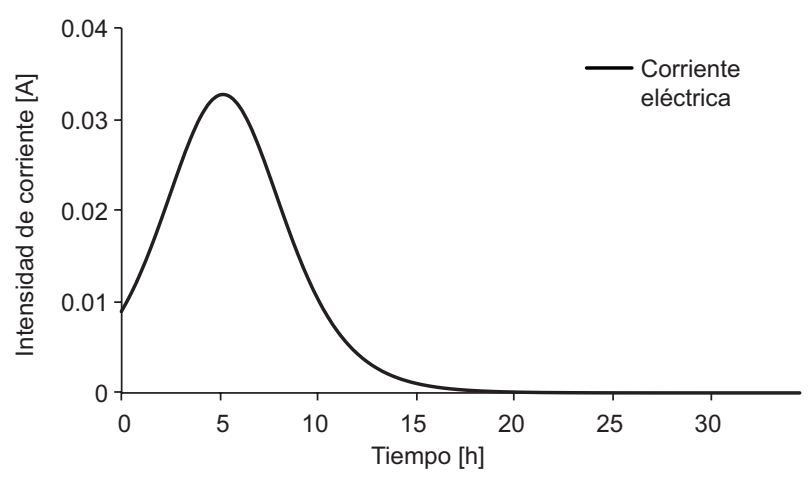

Fig. 13. Gráfica de la intensidad de corriente eléctrica teórica generada por la celda de combustible microbiana

Por otro lado, para la corriente máxima $\left(i_{\text {ext }}\right)$ medida en un resistor óptimo de $1690 \Omega$ se obtuvo un valor de $i_{\mathrm{ext}}=0.057 \mathrm{~mA}$. Al definir la eficiencia microbiana como

$\eta \equiv \frac{i_{\mathrm{ext}}}{i_{\mathrm{x}}} \times 100 \%$

y sustituir los valores de la corriente máxima medida y la corriente teórica máxima, se obtuvo un valor de $\eta$ $=0.18 \%$, que se considera muy bajo. Esto se atribuye a distintos fenómenos de interacción ion-ion de todas las especies presentes, los cuales, dado el sistema, fueron adheridos por otros núcleos "atractores" cargados positivamente, sin contar los fenómenos de conducción eléctrica del sistema. Con lo anterior se ganó aproximadamente uno de cada 500 electrones producidos durante el consumo de glucosa. A pesar de los esfuerzos notables para disminuir la resistencia interna del sistema reduciendo lo más posible la distancia de los electrodos (Timmers et al. 2012), no se obtuvieron más electrones libres.

La eficiencia global de una celda de combustible no se podrá representar únicamente en términos estequiométricos ni de rendimientos microbianos, ya que en el diseño de una CCM intervienen diversos factores, los cuales ya se han mencionado. Sin embargo, la ecuación (31) supone una óptica distinta que indudablemente tiene relación con la eficiencia farádica/termodinámica (Oh et al. 2004, Kim et al. 2005, Ter et al. 2006). Por otro lado, en el cálculo de la eficiencia tradicional, no se considera que existan pérdidas de electrones en la transformación de los productos secundarios de la oxidación de glucosa. Por ello, la carga máxima generada por el consumo de glucosa para la presente celda se puede estimar desde el punto de vista biológico, a través de los rendimientos microbianos.

De este modo, las ecuaciones (30) y (31) constituyen un instrumento alternativo para estimar y cuantificar la eficiencia eléctrica de una celda de combustible microbiana. Al sustituirse los valores de los rendimientos de consumo de fuente de carbono, microbiano y de productos metabólicos, y un modelo poblacional en la ecuación (18), se obtuvo la expresión de la corriente susceptible de formar corriente medible en un resistor externo, lo que proporcionó el punto máximo de corriente que ofrece una CCM.

Desde la óptica de la eficiencia microbiana, ahora los esfuerzos no sólo se enfocarán a nuevos diseños de arquitectura, nuevos materiales, mediadores redox, etcétera, sino también a lograr que los microorganismos no transfieran cargas en la síntesis de productos metabólicos, ya que, como indica la ecuación (1), dichas cargas serán restadas del total y no contribuirán a la formación de energía eléctrica renovable. Así, se sugiere diseñar, desde el punto de vista de la ingeniería genética, un microorganismo electrogénico que produzca la menor cantidad de productos metabólicos y de biomasa. Lo anterior para que todos los electrones producto de la oxidación microbiana sean utilizados en forma de electrones libres que tengan la capacidad de convertirse en corriente eléctrica.

\section{CONCLUSIONES}

El modelo logístico propuesto mostró gran afinidad con los resultados experimentales de biomasa, sustrato y voltaje a circuito abierto, que se refleja en coeficientes de determinación cercanos a la unidad.

La forma de medir la eficiencia eléctrica está fuertemente influenciada por la actividad del crecimiento microbiano. Esto indica que, si bien se han realizado a la fecha notables diseños de arquitectura y operación, no se ha puesto suficiente atención en el metabolismo de los microorganismos para canalizar dicha maquinaria metabólica a la anulación de productos, lo cual posiblemente evitaría el rápido crecimiento de los microorganismos y permitiría alcanzar eficiencias más altas.

A partir de la ecuación (18) puede inferirse que si se diseñaran genéticamente microorganismos con la capacidad de oxidar toda la fuente de carbono 
hasta $\mathrm{CO}_{2}$ y agua, de tal suerte que los rendimientos microbianos fueran nulos, la cantidad de cargas generadas por unidad de tiempo sería mayor. Esto se desprende del modelo, sin considerar los efectos arquitectónicos del diseño de la CCM. Lo anterior tiene sentido si se toma en cuenta que los electrones que producirán energía eléctrica provienen únicamente de la fuente de carbono, por lo cual se dirige la atención a la actividad metabólica del microorganismo.

La ecuación (18) permite cuantificar el aporte temporal de cargas en la oxidación de una fuente de carbono en un microorganismo electrogénico, a partir de los coeficientes estequiométricos y los rendimientos microbianos. Esto posibilita el diseño de una CCM con base en los resultados obtenidos y sin elaborar una celda, algo que no se había realizado con antelación.

\section{REFERENCIAS}

Abrevaya X.C., Sacco N., Mauas P.J.D. y Cortón E. (2011) Archae-based microbial fuel cell operating at high ionic strength conditions. Extremophiles 15 (6), 633-642.

DOI: $10.1007 / \mathrm{s} 00792-011-0394-\mathrm{z}$

Ahn Y. y Logan B.E. (2010) Effectiveness of domestic wastewater treatment using microbial fuel cells at ambient and mesophilic temperatures. Bioresour. Technol. 101 (2), 469-475. DOI: 10.1016/j.biortech.2009.07.039

Ahn Y. y Logan B.E. (2012) A multi-electrode continuous flow microbial fuel cell whit separator electrode assembly design. Appl. Microbiol. Biotechnol. 93 (5), 2241-2248. DOI: $10.1007 / \mathrm{s} 00253-012-3916-4$

APHA (1998). Standard methods for the examination of water and wastewater. 20a ed. American Public Health Association, Washington, EUA, 1325 pp.

Bakhshian S., Kariminia H.R. y Roshandel R. (2011) Bioelectricity generation enhancement in a dual chamber microbial fuel cell under cathodic enzyme catalyzed dye decolorization. Bioresour. Technol. 102 (12), 67616765. DOI: $10.1016 /$ j.biortech.2011.03.060

Behera M. y Ghangrekar M.M. (2009) Performance of microbial fuel cell in response to change in sludge loading rate at different anodic feed $\mathrm{pH}$. Bioresour. Technol. 100 (21), 5114-5121.

DOI: 10.1016/j.biortech.2009.05.020

Bonanni P.S., Schrott G.D., Robuschi L. y Busalmen J.P. (2012) Charge accumulation and electron transfer kinetics in Geobacter sulfurreducens biofilms. Energ. Environ. Sci. 5 (3), 6188-6195.

DOI: $10.1039 / C 2 E E 02672 D$
Catal T., Li K., Bermek H. y Liu H. (2008) Electricity production from twelve monosaccharides using microbial fuel cells. J. Power Sources 175 (1), 196-200.

DOI: 10.1016/j.jpowsour.2007.09.083

Chae K. J., Choi M., Ajayi F.F., Park W., Chang I.S. y Kim I.S. (2008) Mass transport through a proton exchange membrane (Nafion) in microbial fuel cells. Energ. Fuel. 22 (1), 169-176. DOI: 10.1021/ef700308u

Chae K.J., Choi M.J., Lee J.W., Kim K.Y. y Kim I.S. (2009) Effect of different substrates on the performance, bacterial diversity, and bacterial viability in microbial fuel cells. Bioresour. Technol. 100 (14), 3518-3525. DOI:10.1016/j.biortech.2009.02.065

Chaudhuri S.K. y Lovley D.R. (2003) Electricity generation by direct oxidation of glucose in mediatorless microbial fuel cells. Nat. Biotechnol. 21 (10), 12291232. DOI: $10.1038 / \mathrm{nbt} 867$

Chen X., Cui D., Wang X., Wuan X. y Li W. (2015) Porous carbon with defined pore size as anode of microbial fuel cell. Biosens. Bioelectron. 69, 135-141. DOI: 10.1016/j.bios.2015.02.014

Choi S. (2015) Microescale microbial fuel cells: Advanced and challenges. Biosens. Bioelectron. 69, 8-25.

DOI: 10.1016/j.bios.2015.02.021

Daniel D.K., Das Mankidy B., Ambarish K. y Manogari R. (2009). Construction and operation of a microbial fuel cell for electricity generation from wastewater. Int. J. Hydrogen Energ. 34 (17), 7555-7560. DOI: 10.1016/j.ijhydene.2009.06.012

Deeke A., Sleutels T.H., Hamelers H.V. y Buisman C.J. (2012) Capacitive bioanodes enable renewable energy storage in microbial fuel cells. Environ. Sci. Technol. 46 (6), 3554-3560. DOI: 10.1021/es204126r

Di Lorenzo M., Scott K., Curtis T.P. y Head I.M. (2010) Effect of increasing anode surface area on the performance of a single chamber microbial fuel cell. Chem. Eng. J. 156 (1), 40-48. DOI: 10.1016/j.cej.2009.09.031

Dumas C., Mollica A., Ferón D., Baseguy R., Etcheverry L. y Bergel A. (2008) Checking graphite and stainless anodes with an experimental model of marine microbial fuel cell. Bioresour. Technol. 99 (18), 8887-8894. DOI: 10.1016/j.biortech.2008.04.054

Ebert H.J., Picioreanu C., Heijnen J.J. y Van Loosdrecht M.V.M. (2000) A three dimensional numerical study on the correlation of spatial structure, hydrodynamic conditions, and mass transfer and conversion in biofilm. Chem. Eng. Sci. 55 (24), 6209-6222.

DOI: 10.1016/S0009-2509(00)00169-X

Esteve-Núñez A., Rothermich M., Sharma M. y Lovley D. (2005). Growth of Geobacter sulfurreducens under nutrient-limiting conditions in continuous culture. Environ. Microbiol. 7 (5), 641-648. DOI: $10.1111 / j .1462-2920.2005 .00731 . x$ 
Feng Y., Wang X., Logan B.E. y Lee H. (2008) Brewery westwater treatment using air-cathode microbial fuel cells. Appl. Microbiol. Biotechnol. 78 (5), 873-880. DOI: $10.1007 / \mathrm{s} 00253-008-1360-2$

Freguia S., Teh E.H., Boon N., Leung K.M., Keller J. y Rabaey K. (2010) Microbial fuel cells operating on mixed fatty acids. Bioresour. Technol. 101 (4), 12331238. DOI: 10.1016/j.biortech.2009.09.054

Ghadge A.N. y Ghangrekar M.M. (2015) Perfomance of low cost scalable air-cathode microbial fuel cell made from clayware separator using multiple electrodes. Bioresour. Technol. 182, 373-377.

DOI: 10.1016/j.biortech.2015.01.115

Hassan S.H.A., Kim Y.S. y Oh S. (2012) Power generation from cellulose using mixed and pure cultures of cellulose-degrading bacteria in a microbial fuel cell. Enzyme Microb. Technol. 51 (5), 269-273.

DOI: 10.1016/j.enzmictec.2012.07.008

Ieropoulos I.A., Greenman J., Melhuish C. y Hart J. (2005). Comparative study of three types of microbial fuel cell. Enzyme Microb. Technol. 37 (2), 238-245. DOI:10.1016/j.enzmictec.2005.03.006

Janicek A., Fan Y. y Lui H. (2015). Performance and stability of different cathode base materials for use in microbial fuel cells. J. Power Sources 280, 159-165. DOI: 10.1016/j.jpowsour.2015.01.098

Katuri K.P. y Scott K. (2011) On the dynamic response of the anode in microbial fuel cell. Enzyme Microb. Technol. 48 (4-5), 351-358.

DOI: $10.1016 /$ j.enzmictec.2010.12.011

Kim H.J., Park H.S., Hym M.S., Chang I.S., Kim M. y Kim B.H. (2002) A mediator-less microbial fuel cell using a metal reducing bacterium, Shewanella putrefaciens. Enzyme Microb. Technol. 30 (2), 145-152. DOI: $10.1016 / \mathrm{S} 0141-0229(01) 00478-1$

Kim J.R., Min B. y Logan B.E. (2005). Evaluation of procedure to acclimate a microbial fuel cell for electricity production. Appl. Microbiol. Biotechnol. 68 (1), 23-30. DOI: $10.1007 / \mathrm{s} 00253-004-1845-6$

Liu L., Tsyganova O., Lee D.J., Su A., Chang J.S., Wang A. y Ren N. (2012) Anodic biofilm in single-chamber microbial fuel cells cultivated under different temperatures. Int. J. Hydrogen Energ. 37 (20), 1579215800. DOI: $10.1016 /$ j.ijhydene.2012.03.084

Liu X., Wu W. y Gu Z. (2015) Poly (3,4-ethylenedioxythiophene) promotes direct electron transfer at the interface between Shewanella Ioihica and the anode in a microbial fuel cell. J. Power Sources. 277, 110-115. DOI: 10.1016/j.jpowsour.2014.11.129

Logan B.E., Murano C., Scott K., Gray N.D. y Head I.M. (2005) Electricity generation from cysteine in a microbial fuel cell. Water Res. 39 (5), 942-952.

DOI: 10.1016/j.watres.2004.11.019
Logan B.E., Cheng S., Watson V. y Estadt G. (2007) Graphite fiber brush anodes for increased power production in air-cathode microbial fuel cells. Environ. Sci. Technol. 41 (9), 3341-3346.

DOI: $10.1021 / \mathrm{es} 062644 \mathrm{y}$

López S., Prieto M., Dijksta J., Dhanoa M.S. y France J. (2004) Statistical evaluation of mathematical models for microbial growth. Int. J. Food Microbiol. 96 (3), 289-300.

DOI: 10.1016/j.ijfoodmicro.2004.03.026

Lovley D. (2006) Microbial fuel cells: Novel microbial physiologies and engineering approaches. Curr. Opin. Biotechnol. 17 (3), 327-332.

DOI: 10.1016/j.copbio.2006.04.006

Lu N., Zhou S.G., Zhuang L., Zhan J.T. y Ni J.R. (2009) Electricity generation from starch processing wastewater using microbial fuel cell technology. Biochem. Eng. J. 43 (3), 246-252.

DOI: $10.1016 /$ j.bej.2008.10.005

Malvankar N.S., Mester T., Tuominen M.T. y Lovley D.R. (2012) Supercapacitors based on c-Type cytochromes using conductive nanostructured networks of living bacteria. Chem. Phys. Chem. 13 (2), 463-468.

DOI: $10.1002 /$ cphc. 201100865

Milliken C.E. y May H.D. (2007) Sustained generation of electricity by the spore-forming, gram-positive, Desulfitobacterium hufniense strain DCB2. Appl. Microbiol. Biotechnol. 73 (5), 1180-1189.

DOI: $10.1007 / \mathrm{s} 00253-006-0564-6$

Mohan S.V., Saravanan R., Verr Raghavulu S., Mohanakrishna G. y Sarna P.N. (2008) Bioelectricity production from wastewater treatment in dual chambered microbial fuel cell (MFC) using selectively enriched mixed microflora: Efect of catholyte. Bioresour. Technol. 99 (3), 596-603.

DOI: $10.1016 /$ j.biortech.2006.12.026

Nam J.Y., Kim H.W., Lim K.H. y Shin H.S. (2010) Effects of organic loading rates on the continuous electricity generation from fermented wastewater using a singlechamber microbial fuel cell. Bioresour. Technol. 101 (1), S33-S37.

DOI: 10.1016/j.biortech.2009.03.062

Nimje V.R., Chen C.Y., Chen H.R., Chen C.C., Huang Y.M., Tseng M.J., Cheng K.C. y Chang Y.F. (2012) Comparative bioelectricity production from various wastewaters in microbial fuel cells using mixed cultures and a pure strain of Shewanella oneidensis. Bioresour. Technol. 104, 315-323.

DOI: 10.1016/j.biortech.2011.09.129

Oh S., Min B. y Logan B. E. (2004) Cathode performance as a factor in electricity generation in microbial fuel cells. Environ. Sci. Technol. 38 (18), 4900-4904.

DOI: $10.1021 / \mathrm{es} 049422 \mathrm{p}$ 
Oliveira V.B., Simoes M., Melo L.F. y Pinto A.M.F.R. (2013) A 1D mathematical model for a microbial fuel cell. Energy 61, 463-471.

DOI: 10.1016/j.energy.2013.08.055

Ortiz-Martínez V.M., Salar-García M.J., de los Rios A.P., Hernández-Fernández F.J., Egea J.A. y Lozano L.J. (2015) Development in microbial fuel cell modeling. Chem. Eng. J. 217, 50-60.

DOI: 10.1016/j.cej.2015.02.076

Pant D., Van Bogaert G., Diels L. y Vanbroekhoven K. (2010) A review of the substrates used in microbial fuel cells (MFCs) for sustainable energy production. Bioresour. Technol. 101 (6), 1533-1543.

DOI: $10.1016 /$ j.biortech.2009.10.017

Papaharalabos G., Greenman J., Melhuish C. e Ieropoulos I. (2015) A novel small scale Microbial Fuel Cell design for increased electricity generation and waste water treatment. Int. J. Hydrogen Energ. 40 (11), 42634268. DOI:10.1016/j.ijhydene.2015.01.117

Park D. H. y Zeikus J. G. (2000) Electricity generation in microbial fuel cells using neutral red as an electronophore. Appl. Environ. Microbiol. 66 (4), 1292-1297. DOI: 10.1128/AEM.66.4.1292-1297.2000

Park D.H. y Zeikus J.G. (2002) Improved fuel cell and electrode designs for producing electricity from microbial degradation. Biotechnol. Bioeng. 81 (3), 348-355. DOI: 10.1002/bit.10501

Picioreanu C. y Van Loosdrecht M. (2007) A computational model for biofilm-based microbial fuel cells. Water Res. 41 (13), 2921-2940.

DOI: 10.1016/j.watres.2007.04.009

Picioreanu C., van Loosdrecht M., Curtis T.P. y Scott K. (2010) Model based evaluation of the effect of $\mathrm{pH}$ and electrode geometry on microbial fuel cell performance. Bioelectrochem. 78 (1), 8-24.

DOI: 10.1016/j.bioelechem.2009.04.009

Pinto R.P., Srinivasan B., Manuel M.F. y Tartakovsky B. (2010a) A two-population bio-electrochemical model of a microbial fuel cell. Bioresour. Technol. 101 (14), 5256-5265. DOI: 10.1016/j.biortech.2010.01.122

Pinto R.P., Tartakovsky B., Perrier M. y Srinivasan B. (2010b) Optimizing treatment performance of microbial fuel cells by reactor staging. Ind. Eng. Chem. Res. 49 (19), 9222-9229. DOI: 10.1021/ie1004898

Pinto R.P., Srinivasan B., Guiot S.R. y Tartakovsky B. (2011a) The effect of real-time external resistance optimization on microbial fuel cell performance. Water Res. 45 (4), 571-578.

DOI: $10.1016 /$ j.watres.2010.11.033

Pinto R.P., Srinivasan B., Escapa A. y Tartakovsky B. (2011b) Multipopulation model of a Microbial electrolysis cell. Environ. Sci. Technol. 45 (11), 5039-5046. DOI: $10.1021 /$ es104268g
Quan X.C., Quan Y.P. y Tao K. (2012) Effect of anode aeration on the performance and microbial community of an air-cathodemicrobial fuel cell. Chem. Eng. J. 210 (1), 150-156. DOI: 10.1016/j.cej.2012.09.009

Rabaey K., Lissens G., Siciliano S.D. y Verstraete W. (2003) A microbial fuel cell capable lf converting glucose to electricity at high rate and efficiency. Biotech. Lett. 25 (18), 1531-1535. DOI: 10.1023/A:1025484009367

Reiche A. y Kirkwood K.M. (2012) Comparison of Escherichia coli and anaerobic consortia derived from compost as anodic biocatalysis in a glicerol-oxidizin microbial fuel cell. Bioresour. Technol. 123, 318-323. DOI: 10.1016/j.biortech.2012.07.005

Ren H., Torres C.I., Parameswaran P., Rittmann B.E. y Chae J. (2014) Improved current and power density with a micro-scale microbial fuel cell due to a small characteristic length. Biosens. Bioelectron. 61, 587-592. DOI: 10.1016/j.bios.2014.05.037

Ringeisen B.R., Henderson E., Wu P. K., Pietron J., Ray R., Little B., Biffinger J.C. y Jones-Meehan J.M. (2006) High power density from a miniature microbial fuel cell using Shewanella oneidensis DSP10. Environ. Sci. Technol. 40 (8), 2629-2634. DOI: 10.1021/es052254w

Rittman B.E. y McCarty P.L. (2001) Environmental biotechnology: principles and applications. 2a ed. McGraw-Hill Education, Nueva York, 768 pp.

Rodrigo M.A., Cañizares P., García H., Linares J.J. y Lobato J. (2009) Study of the acclimation stage and of the effect of the biodegradability on the performance of a microbial fuel cell. Bioresour. Technol. 100 (20), 4704-4710. DOI 10.1016/j.biortech.2010.04.013

Rodrigo M.A., Cañizares P. y Lobato J. (2010) Effect of the electron acceptors on the performance of a MFC. Bioresour. Technol. 101 (18), 7014-7018.

DOI: $10.1016 /$ j.biortech.2010.04.013

Skinner G.E., Larkin J.W. y Rhodehamel E.J. (1994) Mathematical modeling of microbial growth: A review. J. Food Safety 14 (3), 175-217. DOI: 10.1111/j.1745-4565.1994.tb00594.X

Tao Q., Zhou S., Luo J. y Yuan J. (2015) Nutrient removal and electricity production from wastewater using microbial fuel cell technique. Desalination 365, 92-98. DOI: $10.1016 /$ j.desal.2015.02.021

Timmers R.A., Strik D.P.B.T.B., Hamelers H.V.M. y Buisman C.J.N. (2012) Characterization of the internal resistance of a plant microbial fuel cell. Electrochim. Acta 72, 165-171.

DOI: $10.1016 /$ j.electacta.2012.04.023

Ter Heijne A., Hamelers H.V., De Wilde V., Rozendal R.A. y Buisman C.J. (2006) A bipolar membrane combined with ferric iron reduction as an efficient cathode system in microbial fuel cells. Environ. Sci. Technol. 40 (17), 5200-5205. DOI: 10.1021/es0608545 
Uría N., Berbel X.M., Sánchez O., Muñoz F.X. y Mas J. (2011) Transient storage of electrical charge in biofilms of Shewanella oneidensis $\mathrm{mr}-1$ growing in a microbial fuel cel. Environ. Sci. Technol. 45 (23), 10250-10256. DOI: $10.1021 /$ es2025214

Wen Q., Kong F., Zheng H., Cao D., Ren Y. y Yin J. (2011) Electricity generation from synthetic penicillin wastewater in an air-cathode single chamber microbial fuel cell. Chem. Eng. J. 168 (2), 572-576.

DOI: 10.1016/j.cej.2011.01.025.

Wen Q., Wu Y., Zhao L.X., Sun Q. y Kong F.Y. (2010) Electricity generation and brewery wastewater treatment from sequential anode-cathode microbial fuel cell. J. Zhejiang Univ. Sci. B 11 (2), 87-93.

DOI: 10.1631 jzus.B0900272

Xavier J.B., Picioreanu C. y van Loosdrecht M.C.M. (2004) A modelling study of the activity and structure of biofilms in biological reactors. Biofilms 1 (4). 377391. DOI: $10.1017 / \mathrm{S} 1479050505001560$

Zhang G., Zhao Q., Jiao Y. y Lee D.J. (2015) Long-term operation of manure-microbial fuel cell. Bioresour. Technol. 180, 365-369.

DOI: $10.1016 /$ j.biortech.2015.01.002
Zhao F., Harnisch F., Schröder U., Scholz F., Bogdanoff P. y Herrmann I. (2006) Challenges and Constraints of Using Oxygen Cathodes in Microbial Fuel Cells. Environ. Sci. Technol. 40 (17), 5193-5199. DOI: $10.1021 / \mathrm{es} 060332 \mathrm{p}$

Zhao Y., Li P., Wang X. y Sun Y. (2012) Influence of initial biofilm growth on electrochemical behavior in dual-chambered mediator microbial fuel cell. J. Fuel. Chem. Technol. 40 (8), 967-972. DOI: $10.1016 / \mathrm{S} 1872-5813(12) 60034-6$

Zhi-Dan L.I.U., Jing L.I.A.N., Zhu-Wei D.U. y Li H.R. (2006) Construction of sugar-based microbial fuel cells by dissimilatory metal reduction bacteria. Chin. J. Biotechnol. 22 (1), 131-137.

DOI: $10.1016 / \mathrm{S} 1872-2075(06) 60010-1$

Zwietering M.H., Jongenburger I., Roumbouts F.M. y van't Riet K. (1990) Modeling of the bacterial growth curve. Appl. Environ. Microb. 56 (6), 1875-1881. 